\title{
Innovation in tennis: An overview of research
}

\author{
Miguel Crespo ${ }^{a}$ (D), Dolores Botella-Carrubíb (i) \& José Jabaloyes ${ }^{b}$ (i) \\ a Integrity and Development Department, International Tennis Federation, London, UK. \\ b Universitat Politécnica de València, València, Spain.
}

\begin{abstract}
During the last decades the tennis ecosystem has been immersed in a gradual process of globalisation, professionalisation and commercialisation in an attempt to effectively respond to the increasing challenges of a rapidly evolving environment. This process has seen a number of innovations being applied in the sport. The purpose of this paper is to provide an overview of some of these practices as covered by both researchers and practitioners. It is concluded that research has mainly focused on technological innovations of tennis products created to increase the experience of the players. It is suggested that further studies should investigate service, policy and administrative innovations in the game.
\end{abstract}

Key words: change, evolution, progress, technology

Received: 10 January 2021

Acepted: 15 February 2021

Corresponding author:

Miguel Crespo, ITF Bank Lane,

Roehampton, London SW15

5XZ, Great Britain. Email: Miguel.

Crespo@itftennis.com

\section{INTRODUCTION}

Sport in general and tennis in particular have widely used the term innovation as other areas in society such as arts, culture and health have. Innovation has been understood and defined as a chaotic, complex, iterative and social process that implies the adoption of new practices, structures, or technologies (Wolfe, 1994). As Ratten (2016) indicated, when a given sport is committed to develop ideas with the goal of implementing innovative practices, it can be said that it has an innovation strategy.

Tennis is a multifaceted activity that can be considered a global industry and a business with many ramifications. A truly lifetime and gender-equal sport which is played in 210 countries worldwide by over 87 million players from all ages, skill levels, abilities and conditions, it attracts more than 1 billion fans and can be considered one of the most popular sports (ITF, 2019).

Authors such as Crespo \& Jabaloyes (2020) have highlighted that the wide and strong presence of our game in society drives the sport to adapt, evolve, change and innovate to match the expectations from stakeholders and all those interested.

During the last decades the tennis ecosystem has been immersed in a gradual process of globalisation, professionalisation and commercialisation in an attempt to effectively respond to the increasing challenges of a rapidly evolving environment. This process has seen a number of innovations being applied in the sport. The purpose of this paper is to provide an overview of some of these practices as covered by both researchers and practitioners.

\section{INNOVATION IN TENNIS}

As stated by Garcia del Barrio and Pujol (2015), the tennis industry is one of the most significant providers within the

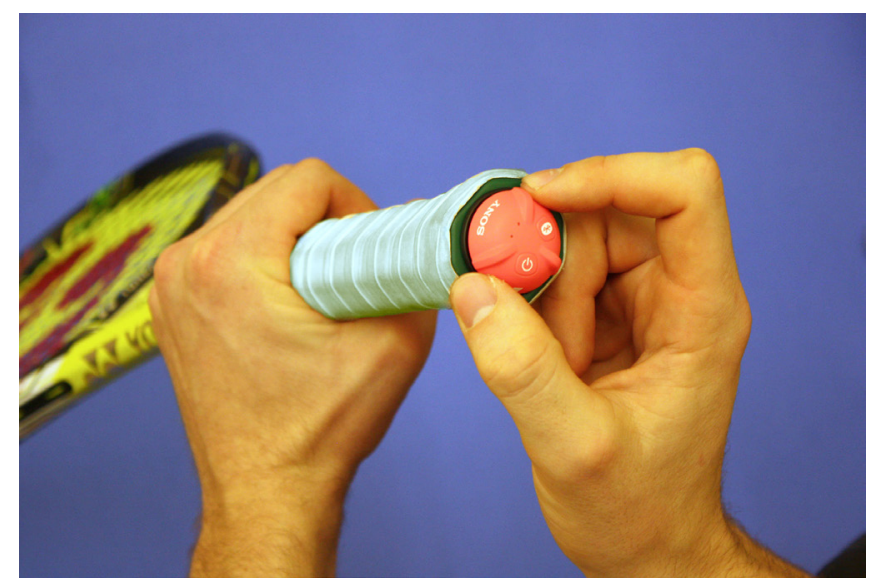

entertainment business. The talent of its top players, the interest of the fans and the number of the playing population are some of the factors the tennis market builds on.

There are special characteristics of tennis such as the need of a given equipment to practice, (i.e., rackets and balls), the unique role of the coaches in the delivery of the sport, and the special features of its competition structure, among other factors, that are considered particularly interesting from an innovation perspective. Therefore, it can be said that, for innovative processes, tennis is especially seen as a favourable scenario.

This phenomenon has been originated from a variety of sources. The firms in the tennis industry have introduced new products and services that have addressed not only the supply side of their industry, but also its demand (Kim and Pennings, 2009). The different tennis organisations have also generated innovative changes in their quest to govern the different areas of the game. The coaches, as the ones who deliver the game at its various levels of practice, are constantly 
producing innovations to improve the tennis experience for the players. The media have transformed the diffusion of the sport towards new levels of sophistication. The players, fans, tournaments and other stakeholders have also favoured considerable innovative changes geared to adapt the game to their needs and expectations.

Innovations in tennis have adopted different forms in terms of products, services, technologies and policies, among others. Several studies have investigated the role, implications and impact of the different types of innovations generated in the game.

In the case of product innovations, authors such as Kim and Pennings (2009) have pointed out that the diffusion and imitation of different product innovations by competing organisations and firms in the tennis industry seem to be largely driven by the legitimacy gained of product endorsements by top professionals and advertising. One aspect which has been studied has been the tennis wear creation (Chae, 2017).

As per service innovation in tennis, the provision of statistical services to players and federations, has been studied by Kovalchik and Reid (2019) who stressed how partnerships can generate new insights to help progress the sport. Tennis organisations such as federations and clubs at different levels are also offering innovative services to their members.

In this scenario, the tennis market is drastically being transformed by technological progress, which has provided access to the game to large numbers of new "consumers of leisure" by using the development of mass media. Studies have also investigated aspects such as sales and marketing in the early introduction of the game (Luitzen, Bollerman, and Delheye, 2015) and training methods in tennis (Ren, 2018). Technical innovations in tennis which have been implemented by the manufacturing industry have received considerable interest from researchers since they put technology to good use in the game. Studies in tennis include, among others the spaghetti strings and the composite rackets as cases of technological innovations than often change the nature of a sport (Gelberg, 1996), or officiating (Hawk-Eye Innovations, 2007; Collins \& Evans, 2008; Mather, 2008; Singh \& Dureja, 2012). Other research about this type of innovations is related to the racquet industry (Kim and Pennings, 2009), the key innovators such as Howard Head (Laudone, Liguori, Muldoon and Bendickson, 2015) or the adapted equipment (Cooke \& Davey, 2007; Buszard, Farrow, Reid \& Masters, 2014) and its influence on game results (Sheridan, 2006).

As per policy innovations in tennis, they have also been studied in the case of the tennis seeding (Sheridan, 2007) or by analysing the views of coaches on the ITF Play \& Stay Campaign as a specific innovative programme (Buszard, Oppicci, Westerbeek \& Farrow, 2020).

Interestingly enough, despite many innovations have been generated by tennis organisations in different areas of the game (i.e., the change of the Davis Cup format, the new naming and branding of the Fed Cup to the Billie Jean King Cup by the ITF, or the creation of the Next Gen event by the ATP), no studies have been found that investigate these changes.

In some cases, innovation in tennis has generated controversy and uncertainty in the market (i.e., innovation in racket materials and design). The potential benefits of some new products or services (i.e., the slower tennis balls) may cause doubts as they could provoke technical uncertainty and uncertainty about the existence of a market for the innovations. This scenario can occur no matter if the innovations are radical, incremental or continuous and its characteristics help to better understand successes and failures of innovations in tennis (Buszard, Farrow, Reid and Masters, 2014).

\section{CONCLUSION}

The summary of research and initiatives described in the previous section allows to conclude that the sport of tennis has seen a continuous process of renewal. As emphasized by authors such as Kim \& Pennings (2009) innovation, apart from the development, production, and launch of new products, it also includes the communication between the organisations or firms and the market.

This study has shown that the tennis ecosystem is implementing different innovations involving a range of resources in order to fulfill the needs and expectations of its stakeholders. In general, this wide variety of initiatives are geared towards increasing participation and fans, improving the performance of the players and providing a better user experience. Many, if not all, of the products and services involve some sort of technological innovation. Some of these innovative practices have received considerable attention from research in an attempt to better understand the key aspects that describe this process.

Research has mainly focused on technological innovations of tennis products created to increase the experience of the players. Therefore, it seems obvious that further studies should investigate service, policy and administrative innovations in the game.

Many of the products or services mentioned offer a unique blend of innovation, experience and accuracy that have revolutionised the tennis world since they are for the betterment of the game. Therefore, it is hoped that tennis will continue to innovate to keep its popularity worldwide.

\section{DECLARATION OF CONFLICTING INTERESTS}

The author(s) declared no potential conflicts of interest with respect to the research, authorship, and/or publication of this article.

\section{FUNDING}

The author(s) received no financial support for the research, authorship, and/or publication of this article.

\section{REFERENCES}

Buszard, T., Farrow, D., Reid, M., \& Masters, R.S.W. (2014). Modifying Equipment in Early Skill Development: A Tennis Perspective, Research Quarterly for Exercise and Sport, 85:2, 218-225. https://doi.org/10.1080/02701367.2014.893054

Collins, H., \& Evans, R. (2008). You cannot be serious! Public understanding of technology with special reference to "Hawk-Eye". Public Understanding of Science, 17(3), 283-308.

Cooke, K., \& Davey, P.R. (2007). Karl Cooke \& Polly R. Davey (2005) Tennis ball diameter: the effect on performance and the concurrent physiological responses, Journal of Sports Sciences, 23:1, 31-39. https://doi.org/10.1080/02640410410001730052

Crespo, M., \& Jabaloyes, J. (2020). Something new? Innovation post COVID-19. A must for tennis. ITF Coaching and Sport Science Review, 81 (29), 6-8. https://www.itf-academy.com/?view=itfview\&academy=103\&itemid=1172 
Chae, M. (2017). An innovative teaching approachto product development: creating tennis wear for female baby boomers. Fashion and Textiles, 4: 13 , 1-17. https://doi.org/10.1186/s40691-017-0098-9

Garcia del Barrio, P., \& Pujol, F. (2015). Sport talent, media value and equal prize policies in tennis. In Rodríguez, P., Késenne, S., and Koning, R. (Eds.). The Economics of Competitive Sports. (pp. 110-151). Edward Elgar Publishing. https://doi.org/10.4337/9781783474769.00015

Gelberg. J. N. (1996). Technology and sport: the case of the ITF, spaghetti strings, and composite rackets. Proceedings and Newsletter of the North American Society for Sport History, 77-78.

Kim, H. E., \& Pennings, J. M. (2009). Innovation and strategic renewal in mature markets: A study of the tennis racket industry. Organization Science, 20(2), 368-383.

Kovalchik, S., \& Reid, M. (2019). The game insight group: A model for academicindustry partnerships for sports statistics innovation. Quality Engineering, 31(1), 23-38. https://doi.org/10.1080/08982112.2018.1519578

Laudone, R., Liguori, E. W., Muldoon, J., \& Bendickson, J. (2015). Technology brokering in action: revolutionizing the skiing and tennis industries. Journal of Management History. 21, (1), 114-134. https://doi.org/10.1108/JMH-03-2014-0068

Luitzen, J, Bollerman, T, \& Delheye, P. (2015). Playing on the Field of Social and Technical Innovation: The Impact of the Sale of Lawn Tennis Sets in the Netherlands, 1874-1887. The International Journal of the History of Sport, 32(9), 1181-1204. https://doi.org/10.1080/09523367.2015.1071356
Mather, G. (2008). Perceptual Uncertainty and Line-Call Challenges in Professional Tennis. Proceedings of the Royal Society B. https://doi.org/10.1098/rspb.2008.0211

Ren, Y. (2018). The application of tennis wall in tennis training and analysis of innovative training methods. In 8th International Conference on Education, Management, Information and Management Society (EMIM 2018) (pp. 372-375). Atlantis Press.

Sheridan, H. (2006). Tennis technologies: de-skilling and re-skilling players and the implications for the game. Sport in society, 9(1), 32-50. https://doi.org/10.1080/17430430500355782

Sheridan, H. (2007). Evaluating Technical and Technological Innovations in Sport. Journal of Sport and Social Issues, 31(2), 179-194. http://dx.doi.org/10.1177/0193723507300485

Singh, B. \& Dureja, G. (2012). Hawk Eye: A Logical Innovative Technology Use in Sports for Effective Decision Making, Sport Science Review, vol. XXI, No. 1-2, April. https://doi.org/10.2478/v10237-012-0006-6

ITF. (2019). Global Tennis Report. https://www.itftennis.com/en/about-us/ organisation/publications-and-resources/publications

Ratten, V. (2016). Sport innovation management: towards a research agenda. Innovation: Management, Policy \& Practice, 18(3), 238-250. https://doi.org/10.1080/14479338.2016.1244471

Wolfe, R.A. (1994). Organizational innovation: review, critique and suggested research directions. Journal of Management Studies, 31, 3, 405-431. https://doi.org/10.1111/j.1467-6486.1994.tb00624.x

Copyright (C) 2021 Miguel Crespo, Dolores Botella-Carrubí \&José Jabaloyes

(c) (i)

This text is under a Creative Commons BY 4.0 license

You are free to Share - copy and redistribute the material in any medium or format - and Adapt the content - remix, transform, and build upon the material for any purpose, even commercially under the following terms:

Attribution: You must give appropriate credit, provide a link to the license, and indicate if changes were made. You may do so in any reasonable manner, but not in any way that suggests the licensor endorses you or your use. 